\title{
A CLÁUSULA DE NÃO CONCORRÊNCIA NO CONTRATO DE EMPREGO
}

\author{
André Araújo de Oliveira
}

\section{RESUMO}

Os empregadores têm adotado prática de cercear a liberdade do empregado, mediante ajuste pactuado expressamente e com correspondente contrapartida, no intuito de afastar as chances de que o conhecimento adquirido no decorrer do primitivo contrato de trabalho migre, num curto espaço de tempo, ao concorrente. Tal prática, não positivada em nosso ordenamento jurídico, tem sido reconhecida como válida pela doutrina e jurisprudência, que se vale, muitas das vezes, do Direito comparado para conferir legalidade ao ajuste na relação de trabalho.

Palavras-chave: cláusula - concorrência - limitação direito fundamental - livre iniciativa

\section{ABSTRACT}

Employers have adopted the practice of curtailing the employee's freedom by means of an express agreement with a corresponding counterpart in order to avoid the chances that the knowledge acquired during the original employment contract will migrate in a short period of time to the competitor. This practice, which is not legally expressed in our legal framework, has been recognized as valid by doctrine and jurisprudence, which is often used in comparative law to confer legality to the adjustment in the employment relationship.

* Mestre em Direitos Difusos e Coletivos pela UNIMES - Universidade Metropolitana de Santos e Doutorando em Direito do Trabalho pela PUC - Pontifícia Universidade Católica de São Paulo; advogado e professor licenciado da Universidade Metodista de São Paulo - UMESP. 


\section{INTRODUÇÃO}

A cláusula de não concorrência caracteriza-se por uma obrigação de não fazer, ou seja, o empregado abstém-se de prestar serviços ao concorrente de seu ex-empregador, por determinado período e mediante certa compensação financeira. Resta analisar, contudo, ante a ausência de regramento próprio em nosso ordenamento jurídico, quais os limites entendidos como válidos para que o acordo não seja declarado nulo pelo Poder Judiciário. Se de um lado tem-se a livre iniciativa como garantia prevista em nossa Constituição Federal, do mesmo modo o direito ao trabalho está assegurado no $5^{\circ}$, XIII, ao estabelecer que "é livre o exercício de qualquer trabalho, oficio ou profissão, atendidas as qualificações profissionais que a lei estabelecer".

O caminho para encontrar o equilibrio quando dois direitos entram em conflito passa por sopesar e identificar quais são os prejuízos no afastamento pontual de determinada garantia. Para tanto, o princípio da proporcionalidade é fundamental para se evitar, dentro do possível, ofensa e limitação às prerrogativas constitucionais.

O direito comparado tem desempenhado importante papel para balizar os contornos das práticas adotadas em nosso país. Mesmo com diferentes regras vigorando em vários países, a doutrina e a jurisprudência, considerando a nossa realidade, tem apontado requisitos a serem observados.

A liberdade de trabalho traduz-se numa conquista histórica que é assegurada pelo ordenamento jurídico vigente como um dos fundamentos do Direito do Trabalho. De outro lado, a necessidade de desenvolvimento econômico não possui caráter absoluto, devendo existir, porém com a constante preocupação em se evitar abusos. As limitações, especialmente com relação à liberdade de trabalho, devem ser analisadas com muita cautela. 
PROTEÇÃO AO TRABALHO E A LIVRE INICIATIVA EVOLUÇÃO LEGISLATIVA NO BRASIL

A Constituição do Império, de 1824, trouxe a previsão, em seu art. 179, XXIV e XXV da impossibilidade de proibição ao trabalho, porém, por outro lado, seguindo modificação na sociedade europeia, também aboliu as corporações de ofício. Ao mesmo tempo em que alça o direito ao trabalho como regra posta, extingue um espaço e método em que o trabalho era desenvolvido até então. A aparente contradição pode ser explicada. As corporações de oficio representavam uma limitação de acesso muito grande à massa de trabalhadores. Havia, na verdade, uma reserva de mercado que deveria cessar para que a liberdade ao trabalho pudesse, de fato, concretizar-se.

Posteriormente, o Código Comercial, de 1850, apontou penalidade para preponentes que atuassem sem concorrência ao empregador. Em que pese limitação, nesse caso mais se coaduna com a boa fé e não se confunde com limitação ao trabalho.

A Constituição de 1891, no art. 72, assegurou direitos concernentes à liberdade e à propriedade.

A Carta Maior de 1934, no art. 121, foi a primeira a tutelar a ordem econômica, ao mesmo tempo em que transferiu à Lei competência para regular as relações de trabalho.

Com maior foco na proteção ao trabalho, a Constituição de 1937, no art. 136, detalhou a importância do trabalho como meio de subsistência do empregado.

A Constituição de 1946 volta a tratar da ordem econômica, atrelando-a ao princípio da justiça social, liberdade de iniciativa e valorização do trabalho humano.

A Constituição de 1969, em seu art. 160, trouxe de forma consolidada as bases da ordem econômica, que tem importância para o desenvolvimento e justiça social, com menção aos princípios da liberdade de iniciativa, valorização do trabalho como condição da dignidade humana, função social da propriedade, harmonia e solidariedade entre as categorias 
sociais de produção e repressão ao abuso do poder econômico, caracterizado pelo domínio dos mercados, eliminação da concorrência e aumento arbitrário dos lucros.

Por fim, a atual Constituição de 1988, em seu art. $1^{\circ}$, também dá ênfase que nossa República tem como fundamento os valores sociais do trabalho e da livre iniciativa. Ainda, o art. $5^{\circ}$, XIII, e art. $6^{\circ}$ da $\mathrm{CF}$, reforçam essas prerrogativas:

\section{Art. $5^{\circ}(\ldots)$ atendidas as qualificações profissionais que a lei estabelecer; assistência aos desamparados, na forma desta Constituição. (destaquei) \\ A LIBERDADE DE TRABALHO E O PRINCÍPIO DA PROPORCIONALIDADE}

XIII - é livre o exercício de qualquer trabalho, oficio ou profissão, Art. $6^{\circ}$ São direitos sociais a educação, a saúde, a alimentação, - trabalho, a moradia, o transporte, o lazer, a segurança, a previdência social, a proteção à maternidade e à infância, a

A liberdade de trabalho concretiza, dá vida e sentido ao Direito do Trabalho, pois seria letra morta um ramo do direito que colocasse obstáculos ao livre exercício de uma profissão. Seria, noutras palavras, letra fria a regulamentar atividades que primeiramente sofreriam violência no livre arbitrio na escolha de um trabalho lícito.

Existe a necessidade de acomodar a liberdade de trabalho, suas exceções e o direito do empregador à livre iniciativa, conforme art. 170 da Constituição Federal:

Art. 170. A ordem econômica, fundada na valorização do trabalho humano e na livre iniciativa, tem por fim assegurar a todos existência digna, conforme os ditames da justiça social, observados os seguintes princípios:

II - propriedade privada;

III - função social da propriedade;

IV - livre concorrência;

VIII - busca do pleno emprego; 
Parágrafo único. É assegurado a todos o livre exercício de qualquer atividade econômica, independentemente de autorização de órgãos públicos, salvo nos casos previstos em lei.

Para que haja harmonia entre essas garantias, necessário explorar o princípio da proporcionalidade, que se subdivide em princípio da necessidade, princípio da adequação e princípio da proporcionalidade em sentido estrito. Pelo princípio da necessidade, precisamos indagar se aquela medida de fato é necessária, se é imprescindivel de ser tomada para que um bem maior seja preservado, ou seja, para limitar um direito fundamental é essencial que haja conclusão pela necessidade da medida. Pelo princípio da adequação, deve o aplicador do Direito verificar se a medida adotada é a mais adequada, mesmo que parcialmente, ou se existiria outra forma de preservar direitos que não aquela escolhida. Por fim, pelo princípio da proporcionalidade em sentido estrito busca-se concluir se a opção escolhida vai trazer os benefícios esperados e, por outro lado, não agredir de forma desnecessária e vultuosa a garantia momentaneamente afastada. É o exercício da razoabilidade para que a agressividade àquele direito, a principio incontroverso, sofra o menor dano possivel.

\section{A CLÁUSULA DE NÃO CONCORRÊNCIA}

Valemo-nos do conceito trazido por Regiane Teresinha de Mello João sobre a cláusula de não concorrência:

“A cláusula de não concorrência consiste na pactuação da abstenção do empregado de ativar-se por conta própria ou para outro empregador, em atividade igual ou semelhante, após o término do contrato de trabalho. "1

Nesse sentido, vale especial atenção à observância da boa-fé objetiva que se espera em toda fase negocial, contemplando, assim, a fase pré-contratual, a fase contratual e a

\footnotetext{
1 JOÃO, Regiane Teresinha de Mello. Cláusula de não concorrência no contrato de trabalho. São Paulo: Saraiva, 2003, pág. 33.
} 
fase pós-contratual. Na fase pré-contratual, não é incomum identificarmos decisões judiciais determinando pagamento de indenização no caso de frustração de contratação que já tivesse sido confirmada pelo empregador. Na fase contratual, a própria legislação vigente respalda esse período como seu fim principal. Por fim, na faze pós-contratual, que mais interessa ao presente artigo, pois limita aquele ex-empregado depois de findo o pacto laboral, tem-se a chamada cláusula e não concorrência.

É importante reconhecer que o conhecimento passou a ter diferenciada relevância se compararmos a décadas atrás, em que a mecanização dava o tom do processo de industrialização. Atualmente, o conhecimento do ser humano agrega expressivo valor aos empregadores. Parte desse conhecimento, inclusive, é adquirido no decorrer do vínculo de emprego, com investimentos realizados pela classe patronal.

No tocante à fase contratual e à cláusula de não concorrência, há previsão expressa no art. 482, alíneas "c" e "g", porém nada é mencionado, diferente da legislação de outros países, conforme se verá mais adiante, quanto à fase pós-contratual. Pode-se entender, contudo, que o art. 44 da CLT ${ }^{2}$, como estipulação ampla, dá margem a ajustes entre empregador e empregado, mas outros países trabalham o tema de forma expressa e direta, evitando, desse modo, insegurança jurídica às partes.

Os motivos que podem justificar a cláusula de não concorrência devem ser significativos e passam pelas seguintes informações de ciência do empregado: conhecimentos técnicos, segredos de fabricação, relação de clientela e, por fim, mesmo não sendo um rol taxativo, a potencialidade de prejuízo. Quanto ao risco de prejuízo, não podemos consi-

\footnotetext{
2 Art. 444 - As relações contratuais de trabalho podem ser objeto de livre estipulação das partes interessadas em tudo quanto não contravenha às disposições de proteção ao trabalho, aos contratos coletivos que lhes sejam aplicáveis e às decisões das autoridades competentes.
}

60 - Revista do Curso de Direito da Faculdade de Humanidades e Direito,

v. 14, n. 14, Edição Especial 2017 
derar a simples chance de uma competição desenrolar-se e gerar incômodo ao ex-empregador como risco de prejuízo. É necessário que, antecipadamente, prejuízos concretos sejam aventados na hipótese de determinada ação do ex-empregado ser colocada em prática.

A cláusula de não concorrência tem como finalidade imediata a preservação dos segredos do próprio empregador, maior interessado na limitação ao trabalho que se pretende pactuar, porém, de outro lado, a finalidade mediata passa pela manutenção de um equilíbrio na competição em determinado mercado, de tal modo que a empresa alcance vantagens por conta de informações privilegiadas obtidas de ex-empregado do concorrente.

\section{DURAÇÃO, FORMA E MOMENTO DA CLÁUSULA DE NÃO CONCORRENCIA}

São variáveis que dependem de cada ordenamento jurídico, à exceção de certos países, como o Brasil, em que o tema ainda não foi regulamentado. De modo geral, alguns pontos acabam sendo uníssonos.

Quanto ao tempo, o Poder Judiciário pode ser instado a corrigir eventual desproporção no tempo ou um ajuste que preveja inatividade permanente. Não se pode aceitar um afastamento definitivo do trabalhador do direito de livremente exercer seu ofício. Ainda, no que toca à desproporção, a depender do ramo de atividade do ex-empregado, um prazo de 2 (dois) anos, por exemplo, pode deixá-lo obsoleto e distante da nova realidade tecnológica, dificultando o retorno ao fim de vigência do pacto. Mesmo após o fim do pacto de não concorrência, deve o trabalhador continuar mantendo a boa-fé objetiva, pois há riscos de responsabilização na seara civil e penal, conforme ainda será mencionado neste artigo.

A forma, ao menos no Brasil, pode ser escrita ou verbal, mas não resta dúvidas de que a forma escrita protege as partes sobremaneira, ainda mais considerando tratar-se de 
limitação de direitos. Nesse sentido os artigos 107 do Código Civil e 442 da CLT $^{3}$. Ainda, importante destacar os benefícios na celebração de pacto que detalhe as obrigações de lado a lado, pois o empregado passa a conhecer suas reais limitações, o valor de sua compensação financeira, o prazo e as atividades proibidas, o espaço territorial, bem como, potencializa a prova a ser levada em eventual discussão judicial.

Quanto ao momento, nada impede a celebração do pacto com cláusula de não concorrência no início do contrato de trabalho, podendo advir também no decorrer da relação empregatícia.

\section{OS PREJUÍZOS E A COMPENSAÇÃO FINANCEIRA}

Como já dito, o empregador tem de antever prejuízos reais na hipótese de o empregado passar a atuar na concorrente de posse de conhecimento adquirido em seu antigo trabalho. Deve esse trabalhador ter tido contato com planos empresarias, projetos em andamento e futuros, segredos da empresa, detalhada relação de clientela. Há quem defenda a possibilidade de o trabalho na concorrência ocorrer, desde que noutra área. Não concordamos com essa posição, pois mesmo noutra área, a proximidade com o novo empregador potencializará o risco de prejuízo.

A compensação financeira deve ser proporcional à limitação imposta ao empregado. É a contrapartida que o empregado receberá por ver o seu direito ao trabalho cerceado por determinado período, motivo pelo qual deve indenizar, de maneira justa, sua inatividade. Pode ser paga de uma única vez ou em prestações, possuindo natureza indenizatória. Se remunera a abstenção de um trabalho, não poderia ter natureza salarial. O pagamento nunca poderá ser feito ao término

\footnotetext{
Art. 107. A validade da declaração de vontade não dependerá de forma especial, senão quando a lei expressamente a exigir.

Art. 442 - Contrato individual de trabalho é o acordo tácito ou expresso, correspondente à relação de emprego. 
de vigência do pacto, pois nesse caso o trabalhador sofreria as consequências da inatividade sem, de forma concomitante, ser compensado por isso.

\section{O DESCUMPRIMENTO DO PACTO}

Caso o empregador descumpra o pacto, o ex-empregado fica livre para buscar sua recolocação, podendo pleitear indenização compensatória pelo descumprimento do avençado. Pode, ainda, requerer o cumprimento do pacto, com disposição em manter sua obrigação inicialmente entabulada e exigindo os correspondentes pagamentos.

Se o pacto for descumprido pelo empregado, terá de restituir os valores já recebidos e reparar os prejuízos causados ao ex-empregador. Outro benefício de o pacto ser celebrado por escrito é a possibilidade de previsão de cláusula penal para já indicar as penalidades na hipótese de descumprimento. De todo modo, mesmo o empregado arcando com as consequências do não cumprimento do ajuste celebrado, em hipótese alguma poderá ele ser obstaculizado de exercer o trabalho que bem entender, ou seja, nem mesmo o Poder Judiciário poderia adentrar em seara particular do trabalhador para impor tal sanção. Os artigos 186 e 187 do Código Civil ${ }^{4}$ também podem atingir o novo empregador caso fique provado que este agiu com dolo ou culpa.

Feitas essas considerações, vê-se que a autonomia da vontade não pode ser absoluta. Eventuais regras entabuladas entre as partes podem, sim, ser objeto de questionamento em juízo, máxime não se identifique um ajuste proporcional e justo. A vontade humana, muitas das vezes, fica relegada a

\footnotetext{
4 Art. 186. Aquele que, por ação ou omissão voluntária, negligência ou imprudência, violar direito e causar dano a outrem, ainda que exclusivamente moral, comete ato ilícito.

Art. 187. Também comete ato ilícito o titular de um direito que, ao exercê-lo, excede manifestamente os limites impostos pelo seu fim econômico ou social, pela boa-fé ou pelos bons costumes.
} 
um segundo plano, pois no Direito do Trabalho está a se falar de norma de ordem pública. Se no próprio direito civil, com código de 2002, a boa-fé pode prevalecer sobre o pactuado expressamente, ainda mais no ramo laboral em que há uma relação de desigualdade entre os contratantes. Há um fim maior a ser alcançado, qual seja, a finalidade e justiça social.

\section{A CLÁUSULA DE NÃO CONCORRENCIA E O DIREITO COMPARADO}

$\mathrm{Na}$ Alemanha, o contrato deve ser firmado por escrito e pode ser celebrado por no máximo 2 (dois) anos, sendo proibido para menores de idade. Perde a validade na justa causa do empregador ou na demissão pelo empregador.

Na Espanha, o prazo máximo de duração é de 2 (dois) anos para trabalhadores técnicos e 6 (seis) meses para os demais trabalhadores, sendo que empregados de alta direção não podem atuar, mesmo na vigência do contrato, a mais de um empregador, salvo com autorização expressa. Há aqui, um dever de fidelidade frente ao empregador e não existe previsão legal de qualquer remuneração para esta finalidade. Já os demais empregados podem atuar, salvo celebração de pacto de não-concorrência. Aqui, de outro modo, há esta liberação a priori, a não ser que exista ajuste em sentido diverso, devendo ocorrer competente compensação financeira.

$\mathrm{Na}$ França, a validade da cláusula se não concorrência apenas se justifica caso a função do empregado seja indispensável ao desenvolvimento da atividade da empresa. As normas coletivas têm disciplinado a matéria e normalmente limitam a 2 (dois anos) sua vigência. Mesmo não existindo a obrigatoriedade legal de compensação financeira, as normas coletivas preveem.

A legislação italiana proíbe a celebração do pacto na vigência do contrato de trabalho. Deve ser o pacto celebrado por escrito, com compensação financeira e pelo prazo máximo de 5 (cinco) anos, prevendo, ainda, limitações claras quanto 
ao objeto, tempo e lugar. São requisitos cumulativos e que se não observados podem ensejar a nulidade do ajuste.

A Bélgica traz um sistema misto que remete a regulamentação à Lei e às normas coletivas. Tem um prazo mais limitado se comparado a outros países, pois aponta o máximo de 12 (doze) meses para a validade do pacto, devendo especificar o local onde o trabalhador não poderá atuar. O pagamento deve ocorrer em parcela única, salvo se o empregador renunciar em 15 dias do término do contrato à continuidade do ajuste.

Vale especial destaque à legislação portuguesa sobre a matéria. Deve ser algo transitório e justificável, além de o trabalhador poder atuar em outra área ou até mesmo desvincular-se do ajuste, desde que indenize. $\mathrm{O}$ argumento é de que poderia o ex-empregado ser um aliado privilegiado da concorrência diante do conhecimento que adquiriu, o que não destoa da justificativa comumente utilizada para implementação do pacto.

$\mathrm{O}$ art. 47, I, da Constituição Portuguesa prevê o seguinte:

1. Todos têm o direito de escolher livremente a profissão ou o género de trabalho, salvas as restrições legais impostas pelo interesse colectivo ou inerentes à sua própria capacidade.

Art. 136, I, do Código do Trabalho de Portugal:

1 - É nula a cláusula de contrato de trabalho ou de instrumento de regulamentação coletiva de trabalho que, por qualquer forma, possa prejudicar o exercício da liberdade de trabalho após a cessação do contrato.

Porém, os artigos 136 e 137 do Código de Trabalho Português, ao mesmo tempo em que ratificam a regra geral da nulidade de cláusula limitativa do exercício do trabalho, aponta exceção e formas para sua implementação:

Artigo $136 .^{\circ}$

Pacto de não concorrência

1 - É nula a cláusula de contrato de trabalho ou de instrumento de regulamentação coletiva de trabalho que, por qualquer 
forma, possa prejudicar o exercício da liberdade de trabalho após a cessação do contrato.

2 - É lícita a limitação da atividade do trabalhador durante o período máximo de dois anos subsequente à cessação do contrato de trabalho, nas seguintes condições:

a) Constar de acordo escrito, nomeadamente de contrato de trabalho ou de revogação deste;

b) Tratar-se de atividade cujo exercício possa causar prejuízo ao empregador;

c) Atribuir ao trabalhador, durante o período de limitação da atividade, uma compensação que pode ser reduzida equitativamente quando o empregador tiver realizado despesas avultadas com a sua formação profissional.

3 - Em caso de despedimento declarado ilícito ou de resolução com justa causa pelo trabalhador com fundamento em ato ilícito do empregador, a compensação a que se refere a alínea c) do número anterior é elevada até ao valor da retribuição base à data da cessação do contrato, sob pena de não poder ser invocada a limitação da atividade prevista na cláusula de não concorrência.

4 - São deduzidas do montante da compensação referida no número anterior as importâncias auferidas pelo trabalhador no exercício de outra atividade profissional, iniciada após a cessação do contrato de trabalho, até ao valor decorrente da aplicação da alínea c) do $n .^{\circ} 2$.

5 - Tratando-se de trabalhador afeto ao exercício de atividade cuja natureza suponha especial relação de confiança ou que tenha acesso a informação particularmente sensível no plano da concorrência, a limitação a que se refere o n. ${ }^{\circ} 2$ pode durar até três anos.

Extrai-se, assim, dos referidos artigos, que o prazo é de 2 (dois) anos, podendo chegar a 3 (três) anos em casos em casos de ocupantes de cargos de confiança, a celebração deve ser por escrito, apenas em atividades que possam causar efetivo prejuízo e com consequente compensação financeira. Por fim, o artigo 138 estabelece a nulidade de acordo entre empregadores que limite a atuação de empregado que tenha trabalhado como temporário: 
Artigo 138.

Limitação da liberdade de trabalho

É nulo o acordo entre empregadores, nomeadamente em cláusula de contrato de utilização de trabalho temporário, que proíba a admissão de trabalhador que a eles preste ou tenha prestado trabalho, bem como obrigue, em caso de admissão, ao pagamento de uma indemnização.

\section{A NÃO CONCORRENCIA E OUTRAS REPERCUSSÕES:}

Como já mencionado, não apenas no Direito do Trabalho o tema da concorrência possui repercussão. Em nossa legislação pátria, o art. $195^{5}$ da Lei de Propriedade

5 Art. 195. Comete crime de concorrência desleal quem:

I - publica, por qualquer meio, falsa afirmação, em detrimento de concorrente, com o fim de obter vantagem;

II - presta ou divulga, acerca de concorrente, falsa informação, com o fim de obter vantagem;

III - emprega meio fraudulento, para desviar, em proveito próprio ou alheio, clientela de outrem;

IV - usa expressão ou sinal de propaganda alheios, ou os imita, de modo a criar confusão entre os produtos ou estabelecimentos;

$\mathrm{V}$ - usa, indevidamente, nome comercial, título de estabelecimento ou insígnia alheios ou vende, expõe ou oferece à venda ou tem em estoque produto com essas referências;

VI - substitui, pelo seu próprio nome ou razão social, em produto de outrem, o nome ou razão social deste, sem o seu consentimento;

VII - atribui-se, como meio de propaganda, recompensa ou distinção que não obteve;

VIII - vende ou expõe ou oferece à venda, em recipiente ou invólucro de outrem, produto adulterado ou falsificado, ou dele se utiliza para negociar com produto da mesma espécie, embora não adulterado ou falsificado, se o fato não constitui crime mais grave;

IX - dá ou promete dinheiro ou outra utilidade a empregado de concorrente, para que o empregado, faltando ao dever do emprego, the proporcione vantagem;

$X$ - recebe dinheiro ou outra utilidade, ou aceita promessa de paga ou recompensa, para, faltando ao dever de empregado, proporcionar vantagem a concorrente do empregador;

XI - divulga, explora ou utiliza-se, sem autorização, de conhecimentos, informações ou dados confidenciais, utilizáveis na indústria, comércio 
Industrial (Lei $\mathrm{n}^{\circ}$. 9.279/1996) tipifica o crime de concorrência desleal.

O Código Civil, em seu art. $1.147^{6}$, também proíbe que o alienante de estabelecimento comercial concorra com o adquirente nos 5 (cinco) anos seguintes à transação havia, salvo se existir ajuste expresso em sentido diverso.

\section{CONCLUSÃO}

Ante o acima exposto, conclui-se que mesmo no silêncio da Lei no tocante à possibilidade de utilização do pacto de não concorrência, doutrina e jurisprudência ${ }^{7}$ aceitam sua estipulação,

ou prestação de serviços, excluídos aqueles que sejam de conhecimento público ou que sejam evidentes para um técnico no assunto, a que teve acesso mediante relação contratual ou empregatícia, mesmo após o término do contrato;

XII - divulga, explora ou utiliza-se, sem autorização, de conhecimentos ou informações a que se refere o inciso anterior, obtidos por meios ilícitos ou a que teve acesso mediante fraude; ou

XIII - vende, expõe ou oferece à venda produto, declarando ser objeto de patente depositada, ou concedida, ou de desenho industrial registrado, que não o seja, ou menciona-o, em anúncio ou papel comercial, como depositado ou patenteado, ou registrado, sem o ser;

XIV - divulga, explora ou utiliza-se, sem autorização, de resultados de testes ou outros dados não divulgados, cuja elaboração envolva esforço considerável e que tenham sido apresentados a entidades governamentais como condição para aprovar a comercialização de produtos.

Pena - detenção, de 3 (três) meses a 1 (um) ano, ou multa.

$\S 1^{\circ}$ Inclui-se nas hipóteses a que se referem os incisos XI e XII o empregador, sócio ou administrador da empresa, que incorrer nas tipificações estabelecidas nos mencionados dispositivos.

$\S 2^{\circ} \mathrm{O}$ disposto no inciso XIV não se aplica quanto à divulgação por órgão governamental competente para autorizar a comercialização de produto, quando necessário para proteger o público.

6 Art. 1.147. Não havendo autorização expressa, o alienante do estabelecimento não pode fazer concorrência ao adquirente, nos cinco anos subseqüentes à transferência.

7 CLÁUSULA DE NÃO-CONCORRÊNCIA. INDENIZAÇÃO COMPENSATÓRIA. VALIDADE. Embora a legislação trabalhista seja omissa quanto ao tema ventilado. O artigo 444 da CLT prevê, como regra, pactuação livre das

68 - Revista do Curso de Direito da Faculdade de Humanidades e Direito,

v. 14, n. 14, Edição Especial 2017 
desde que observações os requisitos mencionados, quais sejam, tempo razoável, demonstração de efetivo prejuízo ao empregador, compensação financeira justa, limitação que considere uma área geográfica e ramo de atuação. Apenas no tocante à delimitação territorial, pode ser prescindivel, pois na era da informática a concorrência pode não encontrar barreiras.

Destaca-se, ainda, por fim, que a concorrência desleal não exige permanência (diferente da negociação habitual prevista no art. 482 da CLT), ou seja, pode ocorrer num único ato.

\section{REFERENCIAS}

BARACAT, Eduardo Milléo. A boa-fé no direito individual do trabalho. São Paulo: LTr, 2003.

BARROS, Alice Monteiro de. Curso de direito do trabalho. 5. Ed. São Paulo. Ltr, 2009.

CARRION, Valentin. Comentários à consolidação das leis do trabalho. 31 . ed. atual. por Eduardo Carrion. São Paulo: Saraiva, 2006.

DELGADO, Maurício Godinho. Curso de Direito do Trabalho. 5. ed. São Paulo: LTr, 2006.

JOÃO, Regiane Teresinha de Mello. Cláusula de não concorrência no contrato de trabalho. São Paulo: Saraiva, 2003.

NASCIMENTO, Amauri Mascaro. Iniciação ao direito do trabalho. 32. ed. São Paulo: LTr, 2006.

cláusulas contratuais, desde que não haja violação às disposições legais, coletivas, e, às decisões das autoridades competentes. A cláusula de não-concorrência é a obrigação pela qual o empregado se compromete a não praticar pessoalmente ou por meio de terceiro ato de concorrência para com o (a) empregador (a). Trata-se de uma obrigação de natureza moral e de lealdade. Não há de se falar em ofensa ao Princípio da Liberdade de Trabalho, quando o pacto de não-concorrência foi livremente pactuado e há previsão do limite temporal da restrição, mediante justa retribuição, como é o caso vertente. Revelado o descumprimento da referida avença, cabe ao obreiro restituir à empregadora o valor proporcional ao tempo que falta para completar os 12 meses de restrição. Processo nº 16201820125020. Orgão Julgador: 4ª TURMA. 22/10/2013. Relatora: Patricia Therezinha De Toledo. 